\title{
Ibrutinib targets mutant-EGFR kinase with a distinct binding conformation
}

\author{
Aoli Wang ${ }^{1,2, *}$, Xiao-E Yan ${ }^{3, *}$, Hong Wu ${ }^{1,2, *}$, Wenchao Wang ${ }^{1,4, *}$, Chen Hu ${ }^{1,2}$, Cheng \\ Chen $^{1,2}$, Zheng Zhao ${ }^{1,4}$, Peng Zhao ${ }^{3}$, Xixiang Lí ${ }^{1}$, Li Wang ${ }^{1,2}$, Beilei Wang ${ }^{1,2}$, Zi Ye ${ }^{5}$, \\ Jinhua Wang ${ }^{6,9}$, Chu Wang ${ }^{5}$, Wei Zhang7, Nathanael S. Gray ${ }^{6,9}$, Ellen L. Weisberg ${ }^{8}$, \\ Liang Chen7, Jing Liu' ${ }^{1,4}$, Cai-Hong Yun ${ }^{3}$, Qingsong Liu ${ }^{1,2,4}$ \\ ${ }^{1}$ High Magnetic Field Laboratory, Chinese Academy of Sciences, Anhui, Hefei 230031, P. R. China \\ ${ }^{2}$ University of Science and Technology of China, Anhui, Hefei 230036, P. R. China \\ ${ }^{3}$ Institute of Systems Biomedicine, Department of Biophysics, Beijing Key Laboratory of Tumor Systems Biology and Center \\ for Molecular and Translational Medicine, School of Basic Medical Sciences, Peking University Health Science Center, Beijing \\ 100191, P. R. China \\ ${ }^{4}$ Hefei Science Center, Chinese Academy of Sciences, Anhui, Hefei 230031, P. R. China \\ ${ }^{5}$ Synthetic and Functional Biomolecules Center, Beijing National Laboratory for Molecular Sciences, Key Laboratory of \\ Bioorganic Chemistry and Molecular Engineering of Ministry of Education, College of Chemistry and Molecular Engineering, \\ Peking-Tsinghua Center for Life Sciences, Peking University, Beijing 100871, P. R. China \\ ${ }^{6}$ Department of Cancer Biology, Dana-Farber Cancer Institute, Harvard Medical School, Boston, MA 02115, USA \\ ${ }^{7}$ Collaborative Innovation Center of Cancer Medicine, National Institute of Biological Sciences, Beijing 102206, P. R. China \\ ${ }^{8}$ Department of Medical Oncology, Dana Farber Cancer Institute, Harvard Medical School, Boston, MA 02115, USA \\ ${ }^{9}$ Department of Biological Chemistry and Molecular Pharmacology, Harvard Medical School, Boston, MA 02115, USA \\ *These authors contributed equally to this work
}

Correspondence to: Jing Liu, email: jingliu@hmfl.ac.cn Cai-Hong Yun, email: yunch@hsc.pku.edu.cn

Qingsong Liu, email: qsliu97@hmfl.ac.cn

Keywords: Ibrutinib, EGFR kinase, DFG-in/c-Helix-out, inactive conformation, NSCLC

Received: June 08, 2016

Accepted: September 05, 2016

Published: September 10, 2016

\section{ABSTRACT}

Ibrutinib, a clinically approved irreversible BTK kinase inhibitor for Mantle Cell Lymphoma (MCL) and Chronic Lymphocytic Leukemia (CLL) etc, has been reported to be potent against EGFR mutant kinase and currently being evaluated in clinic for Non Small Cell Lung Cancer (NSCLC). Through EGFR wt/mutant engineered isogenic BaF3 cell lines we confirmed the irreversible binding mode of Ibrutinib with EGFR wt/mutant kinase via Cys797. However, comparing to typical irreversible EGFR inhibitor, such as WZ4002, the washing-out experiments revealed a much less efficient covalent binding for Ibrutinib. The biochemical binding affinity examination in the EGFR L858R/T790M kinase revealed that, comparing to more efficient irreversible inhibitor WZ4002 (Kd: $0.074 \mu \mathrm{M})$, Ibrutinib exhibited less efficient binding (Kd: $0.18 \mu \mathrm{M})$. An X-ray crystal structure of EGFR (T790M) in complex with Ibrutinib exhibited a unique DFG-in/cHelix-out inactive binding conformation, which partially explained the less efficiency of covalent binding and provided insight for further development of highly efficient irreversible binding inhibitor for the EGFR mutant kinase. These results also imply that, unlike the canonical irreversible inhibitor, sustained effective concentration might be required for Ibrutinib in order to achieve the maximal efficacy in the clinic application against EGFR driven NSCLC. 


\section{INTRODUCTION}

Ibrutinib, an irreversible BTK kinase inhibitor, has been extensively studied in the B-Cell related malignances due to the effective roles for interruption of the B-Cell Receptor (BCR) mediated signaling pathways $[1,2]$. In late 2013 and early 2014 it has been approved for MCL and CLL clinical application respectively [3-6]. Currently it is also being actively evaluated in the clinic for the Diffuse Large B-Cell Lymphoma (DLBCL), Multiple Myeloma (MM) and Acute Myeloid Leukemia (AML) either as a single agent or combination with other chemotherapies or biological therapies [2, 7-9]. Recently Ibrutinib has also been reported to be effective against EGFR mutant Non-Small Cell Lung Cancer (NSCLC) and now being tested in phase I/II clinical trial.[10] Ibrutinib forms a covalent bond with BTK kinase in the Cys481 amino acid to exert the irreversible binding.[11] Proteomic study with ABPP approach also demonstrated that ibrutinib could modify the EGFR wide type kinase via Cys797 in A431 cells [12]. Given the clinical importance of EGFR mutant driven NSCLC, we explored the detailed binding mechanism of Ibrutinib with mutant EGFR (L858R, Del19, L858R/T790M) which revealed a relatively less efficient irreversible binding due to a unique DFG-in/c-Helix-out inactive binding conformation. We envision that insight of this special binding mechanism may help to develop more effective Ibrutinib pharmacophore based EGFR mutant sensitive inhibitors for NSCLC and also direct the proper design of the clinical trial to achieve the maximal efficacy.

\section{RESULTS}

\section{Ibrutinib irreversibly binds to EGFR mutant via Cys797}

Given the fact that both EGFR and BTK kinase bear a similarly accessible cysteine residue (Cys481 in BTK and Cys797 in EGFR) in the hinge binding area, we first tried to determine if ibrutinib binds irreversibly to EGFR mutant as it binds to BTK kinase [13]. We first made a panel of EGFR wt/mutant engineered $\mathrm{BaF} 3$ isogenic cell lines whose growth is dependent on either TEL fusion with the EGFR kinase domain (TEL-EGFR) or full-length EGFR (F-EGFR) harboring gain-of-function mutations with or without the Cys797 mutation (C797S).[14] Ibrutinib did not affect wt EGFRexpressing BaF3 cells, wt TEL-EGFR, or the TEL-EGFR (C797S) mutation $\left(\mathrm{GI}_{50}:>10 \mu \mathrm{M}\right)$. (Table 1) It potently inhibited the TEL-EGFR (L858R) $\left(\mathrm{GI}_{50}: 0.062 \mu \mathrm{M}\right)$ mutation, however significantly lost activity against TELEGFR (L858R/C797S) $\left(\mathrm{GI}_{50}: 3.9 \mu \mathrm{M}\right)$. It also exhibited activity against TEL-EGFR (T790M) $\left(\mathrm{GI}_{50}: 0.16 \mu \mathrm{M}\right)$, however lost around 10-fold potency against TEL-EGFR $(\mathrm{L} 858 \mathrm{R} / \mathrm{T} 790 \mathrm{M})\left(\mathrm{GI}_{50}: 1.7 \mu \mathrm{M}\right)$. Ibrutinib completely lost activity against cell lines harboring the EGFR C797S mutation. Interestingly, Ibrutinib was approximately 10 fold more potent against full length F-EGFR (L858R) transformed BaF3 cells than the TEL-EGFR (L858R) $\left(\mathrm{GI}_{50}: 0.004 \mu \mathrm{M}\right.$ vs. $\left.0.062 \mu \mathrm{M}\right)$. Similarly, ibrutinib lost around 10-fold activity against F-EGFR (L858R/T790M) $\left(\mathrm{GI}_{50}: 0.061 \mu \mathrm{M}\right)$ and also significantly lost activity when $\mathrm{C} 797 \mathrm{~S}$ was introduced $\left(\mathrm{GI}_{50}: 3.8 \mu \mathrm{M}\right)$. A similar trend was observed for the EGFR (Del 19) mutation. These results recapitulated the results observed from the intact cancer cell lines and suggest that ibrutinib is highly potent against EGFR (L858R) and EGFR (Del 19) mutations, however moderately active when the T790M gatekeeper mutation is introduced. Comparably, the reversible version of ibrutinib, i.e. PCI-R, lost approximately 20-50 fold activities as compared to ibrutinib itself. (Supplementary Figure S1) Combining the results observed with ABPP approach for EGFR wt in A431 cells, these results suggest that ibrutinib works through formation of a covalent bond with Cys797. Irreversible EGFR inhibitors WZ4002, CO-1686 and AZD9291 demonstrated similar activities, except they also moderately inhibited the growth of wt EGFRexpressing $\mathrm{BaF} 3$ cells, indicating potential off-target effects. While reversible EGFR inhibitor exhibited similar trend with PCI-R except that it also potently inhibits the EGFR L858R mutant.

\section{Washing-out experiment revealed ibrutinib's less irreversible inhibition efficiency}

To further elucidate the possible irreversible binding mode, we then conducted a washing-out experiment in H1975 cell (EGFR L858R/T790M) using an anti-proliferation assay. The results showed that WZ4002 worked as a typical irreversible inhibitor that exhibited apparent inhibitory activity after even just $1 \mathrm{~h}$ pre-drug treatment. However, ibrutinib only exhibited inhibitory activities upon $72 \mathrm{~h}$ continuous drug treatment. (Figure 1A) With $4 \mathrm{~h}$ pre-drug treatment in the H1975 cell line, WZ4002 $(0.3 \mu \mathrm{M})$ completely suppressed EGFR Y1068 auto-phosphorylation within $24 \mathrm{~h}$ after drug removal. However, at the $\mathrm{GI}_{50}$ concentration $(1 \mu \mathrm{M})$ of ibrutinib, the EGFR Y1068 auto-phosphorylation signal returned following $8 \mathrm{~h}$ after drug removal, which suggests a less efficient irreversible inhibition. (Figure 1B) The similar phenotype was observed in the HCC 827 cell that harbors EGFR del19 deletion despite of the strong in vitro anti-proliferation efficacy comparing to H1975 cells. (Figure 1C, 1D) These results indicated that ibrutinib was a unique irreversible EGFR inhibitor comparing to other typical ones and its inhibitory efficacy might require sustained drug exposure to maintain the signaling pathway suppression. Further testing biochemical binding affinity of ibrutinib with purified EGFR L858R/T790M kinase protein revealed that it 
Table 1: Ibrutinib anti-proliferation efficacy against EGFR mutant isogenic BaF3 cell lines

\begin{tabular}{|c|c|c|c|c|c|c|}
\hline $\begin{array}{c}\text { Isogenic Cell } \\
\text { Line } \\
\text { GI50 }(\mu \mathrm{M})\end{array}$ & WZ-4002 & Gefitinib & Ibrutinib & PCI-R & CO-1686 & AZD9291 \\
\hline Structure & o- & & 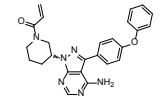 & & & \\
\hline WT-BaF3 & $>10$ & $>10$ & $>10$ & 7.5 & 0.97 & 2.7 \\
\hline $\begin{array}{l}\text { BaF3-tel-wt- } \\
\text { EGFR }\end{array}$ & 1.6 & 5.2 & $>10$ & $>10$ & 2.8 & 1.8 \\
\hline $\begin{array}{l}\text { BaF3-tel-WT- } \\
\text { EGFR-C797S }\end{array}$ & 1.3 & 0.11 & $>10$ & $>10$ & 1.3 & 1.3 \\
\hline $\begin{array}{l}\text { BaF3-tel- } \\
\text { EGFR-L858R }\end{array}$ & 0.0023 & 0.0022 & 0.062 & 4.7 & 0.0063 & 0.0017 \\
\hline $\begin{array}{l}\text { BaF3-tel- } \\
\text { EGFR-L858R- } \\
\text { C797S }\end{array}$ & 3.7 & 0.006 & 3.9 & 9.3 & 1.6 & 0.6 \\
\hline $\begin{array}{l}\text { BaF3-tel- } \\
\text { EGFR-T790M }\end{array}$ & 0.11 & $>10$ & 0.16 & $>10$ & 0.13 & 0.022 \\
\hline $\begin{array}{l}\text { BaF3-tel- } \\
\text { EGFR-T790M- } \\
\text { C797S }\end{array}$ & $>10$ & $>10$ & $>10$ & $>10$ & 1.2 & 1.6 \\
\hline $\begin{array}{l}\text { BaF3-tel- } \\
\text { EGFR-L858R- } \\
\text { T790M }\end{array}$ & 0.0012 & 2.8 & 1.7 & 3.1 & 0.038 & 0.007 \\
\hline $\begin{array}{l}\text { BaF3-tel- } \\
\text { EGFR-T790M- } \\
\text { L858R-C797S }\end{array}$ & 4.5 & $>10$ & $>10$ & $>10$ & 0.88 & 1.7 \\
\hline $\begin{array}{l}\text { BaF3-FL- } \\
\text { EGFR-L858R }\end{array}$ & 0.003 & 0.007 & 0.004 & 2.1 & 0.015 & 0.002 \\
\hline $\begin{array}{l}\text { BaF3-FL- } \\
\text { EGFR-L858R- } \\
\text { T790M }\end{array}$ & 0.0017 & 7.2 & 0.061 & 1.3 & 0.0014 & 0.0021 \\
\hline $\begin{array}{l}\text { BaF3-FL- } \\
\text { EGFR-T790M- } \\
\text { L858R-C797S }\end{array}$ & 1.2 & 3.7 & 3.8 & 3.5 & 0.73 & 1.7 \\
\hline $\begin{array}{l}\text { BaF3-FL- } \\
\text { EGFR-del19- } \\
\text { T790M } \\
\end{array}$ & 0.0016 & 2.9 & 0.34 & 1.1 & $<0.0003$ & $<0.0003$ \\
\hline $\begin{array}{l}\text { BaF3-FL- } \\
\text { EGFR-del19- } \\
\text { T790M-C797S }\end{array}$ & 0.83 & 1.6 & $>10$ & $>10$ & 0.63 & 0.36 \\
\hline
\end{tabular}

beard a binding $\mathrm{Kd}$ of $0.18 \mu \mathrm{M}$, while more efficient irreversible inhibitor WZ4002 displayed a binding Kd of $0.074 \mu \mathrm{M}$. (Figure 1E) This indicated that the less efficiency of the irreversible binding might be due to the less efficient binding.

\section{Ibrutinib adopted a unique DFG-in/c-Helix-out inactive binding conformation}

To further explore this special phenotype, we determined a high-resolution crystal structure of EGFR 
A

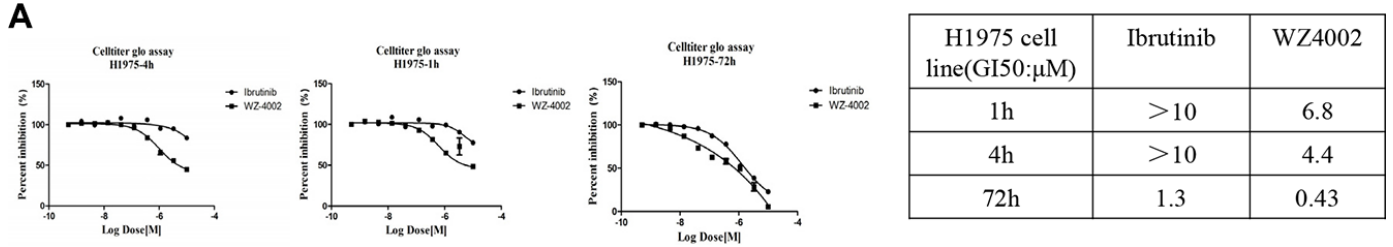

B

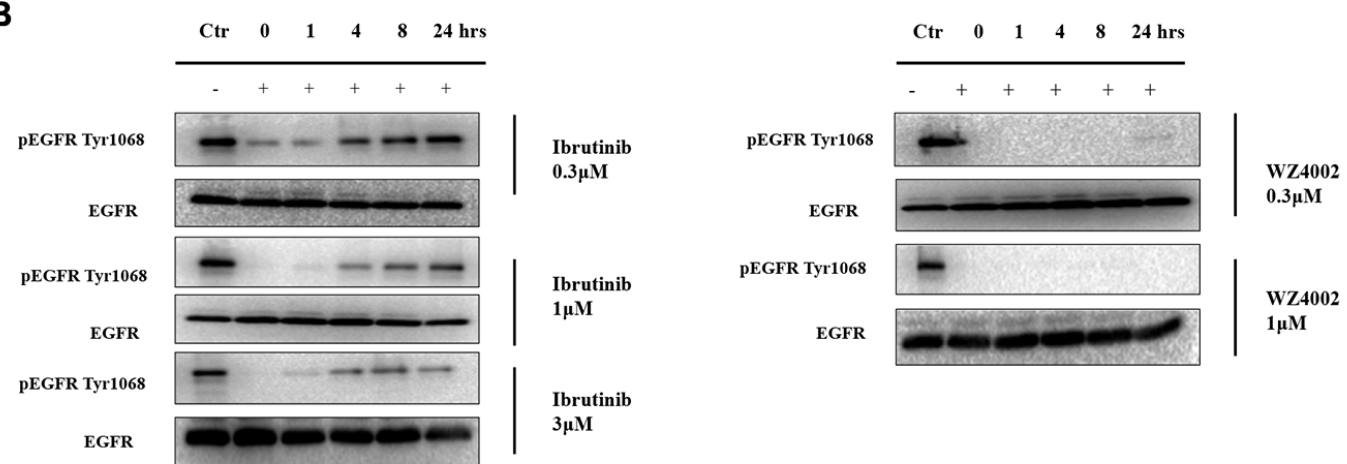

C

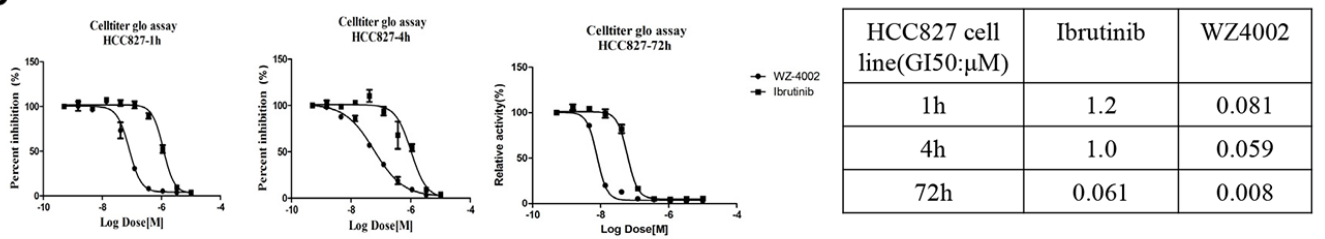
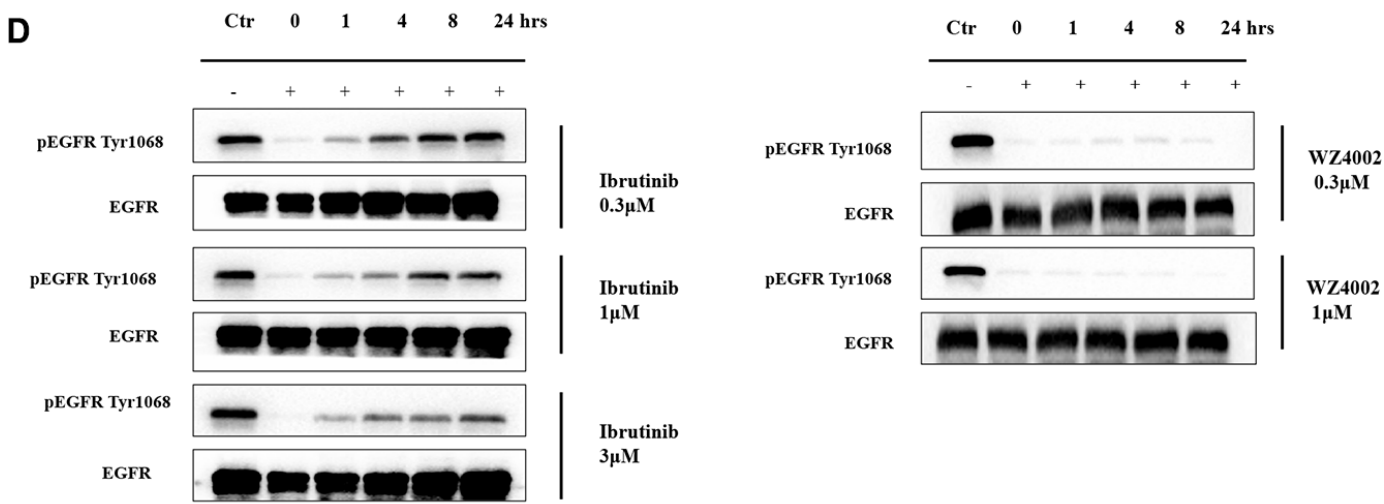

E

Ibrutinib---EGFR L858R/T790M

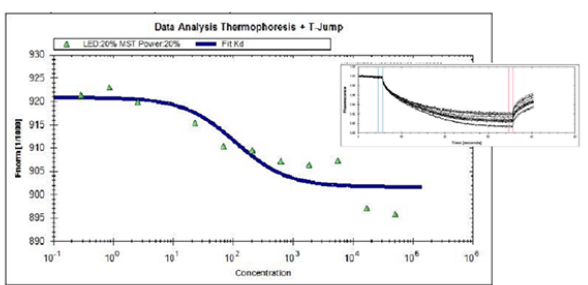

Kd: $0.18 \mu \mathrm{M}$

WZ4002---EGFR L858R/T790M

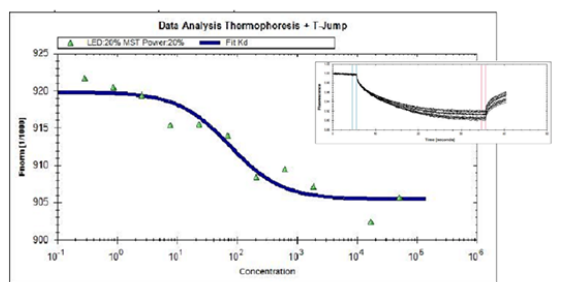

Kd: $0.074 \mu \mathrm{M}$

Figure 1: Ibrutinib irreversible binding mode exploration. (A) Ibrutinib and WZ4002 anti-proliferation effects against the H1975 cell line by removal of drug after $1 \mathrm{~h}, 4 \mathrm{~h}$ and $72 \mathrm{~h}$ treatment. (B) Ibrutinib and WZ4002 inhibitory effects on EGFRY1068 autophosphorylation in the $\mathrm{H} 1975$ cell line at different time points by removal of drug after $4 \mathrm{~h}$ pretreatment. (C) Ibrutinib and WZ4002 antiproliferation effects against the HCC 827 cell line by removal of drug after $1 \mathrm{~h}, 4 \mathrm{~h}$ and $72 \mathrm{~h}$ treatment. (D) Ibrutinib and WZ4002 inhibitory effects on EGFRY1068 auto-phosphorylation in the HCC827 cell line at different time points by removal of drug after $4 \mathrm{~h}$ pretreatment. (E) Micro-Scale Thermophoresis (MST) technology based binding Kd test of Ibrutinib and WZ4002 against EGFR T790M/L858R kinase. 


\begin{tabular}{|c|c|}
\hline \multicolumn{2}{|l|}{ Data collection** } \\
\hline Space group & $\mathrm{C} 2$ \\
\hline \multicolumn{2}{|l|}{ Cell dimensions } \\
\hline$a, b, c(\AA)$ & $168.2,74.4,120.5$ \\
\hline$\left(^{\circ}\right)$ & $90.0,118.3,90.0$ \\
\hline Resolution ( $\AA$ ) & $50.0-1.95(2.02-1.95)$ \\
\hline $\mathrm{R}_{\text {pim }}$ & $0.095(0.450)$ \\
\hline$I / I$ & $7.9(2.3)$ \\
\hline Completeness (\%) & $99.6(99.8)$ \\
\hline Redundancy & $3.2(3.2)$ \\
\hline \multicolumn{2}{|l|}{ Refinement } \\
\hline Resolution ( $)$ & $41.6-1.95$ \\
\hline No. reflections & 94949 \\
\hline$R_{\text {work }} / R_{\text {free }}$ & $0.200 / 0.221$ \\
\hline \multicolumn{2}{|l|}{ No. atoms } \\
\hline Protein & 9690 \\
\hline Ligand/ion & 156 \\
\hline Water & 950 \\
\hline \multicolumn{2}{|l|}{$B$-factors } \\
\hline Protein & 28.4 \\
\hline Ligand/ion & 24.0 \\
\hline Water & 37.7 \\
\hline \multicolumn{2}{|l|}{ R.m.s. deviations } \\
\hline Bond lengths $(\AA)$ ) & 0.010 \\
\hline Bond angles $\left(^{\circ}\right)$ & 1.403 \\
\hline PDB ID & $4 \mathrm{YNJ}$ \\
\hline
\end{tabular}

*One crystal was used to collect data for determination of this structure.

**Values in parentheses are for highest-resolution shell.

T790M in complex with ibrutinib (PDB ID: 4YNJ, Table 2 and Supplementary Figure S2). Covalent binding of ibrutinib to EGFR Cys797 was confirmed in this structure, and we found that Ibrutinib binds EGFR T790M in inactive conformation, although this protein by itself crystallizes in active conformation [15]. Four EGFR T790M protein molecules were observed in the asymmetric unit of the T790M+Ibrutinib structure, each binding to an ibrutinib molecule. (Figure 2A) Interestingly, despite the same covalent bonds formed between the Cys797 of EGFR and acrylamide of ibrutinib, the four ibrutinib molecules adopt two slightly different conformations in the piperidine-acrylamide moiety. (Figure 2B) The ibrutinib bound EGFR T790M adopts the DFG-in/C-helix-out inactive conformation which closely resembles the previously reported EGFR structure in inactive conformation (PDB ID 2GS7, Figure 2C) [16]. The Met790 side-chain well fits to the inhibitor and make beneficial hydrophobic interaction with the phenyl ring attached to pyrazolopyrimidine. (Figure 2C) This may explain the relative tolerance of ibrutinib to the drugresistant T790M-bearing EGFR mutants comparing to the first generation inhibitor Gefitinib.

Since HKI-272 also covalently binds to EGFR in the inactive conformation, we compared the structure of EGFR T790M in complex with ibrutinib to the structure of EGFR T790M in complex with HKI-272 [15]. Two major differences were revealed in the superimposition (Figure 2D) First, the beneficial interaction between Met790 side-chain and the phenyl ring attached to the 
pyrazolopyrimidine moiety of ibrutinib does not present in the HKI-272 bound EGFR T790M structure. The cyano group attached to the quinolone moiety in HKI-272 prevents this beneficial interaction due to steric hindrance. Second, Ibrutinib does not interact with Phe856 in the DFG motif as HKI-272 and Lapatinib do [15, 17]. One more methylene group presents in the linkage between the terminal pyridine ring and the phenyl ring attached to the quinolone moiety in HKI-272 (similar design applies to Lapatinib). This extra methylene pushes the terminal pyridine (phenyl in the case of Lapatinib) more deeply into the ATP binding pocket, driving it close to the DFG motif. The terminal phenyl thus makes direct hydrophobic interaction with Phe856. This interaction is not observed with ibrutinib since its terminal phenyl ring does not go deeply enough in the ATP binding pocket. This explains why ibrutinib binds EGFR in a distinct DFG-in/C-helix- out conformation, while HKI-272 (and Lapatinib) binds EGFR in a DFG-partially-out/C-helix-out conformation. The relatively weaker binding affinity of ibrutinib to EGFR(L858R/T790M) may be related to this property, too, since the inhibitor-DFG interaction would enhance the binding of the drug.

WZ4002 is another third-generation covalent inhibitor that works well with EGFR T790M. Superimposition of the T790M+Ibrutinib structure with the previously reported T790M+WZ4002 co-crystal structure (PDB ID 3IKA) [18-21] disclosed the distinct difference between these two inhibitors. Ibrutinib forces EGFR kinase to adopt a distinct DFG-in/C-helix-out inactive conformation. While WZ4002 binds to the DFGpartially-out/C-helix-in active conformation. (Figure 2E) The bulky o-bridged biphenyl moiety of ibrutinib can be accommodated by EGFR in the inactive state only,

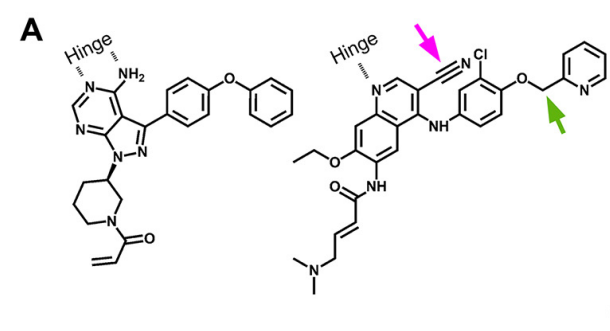

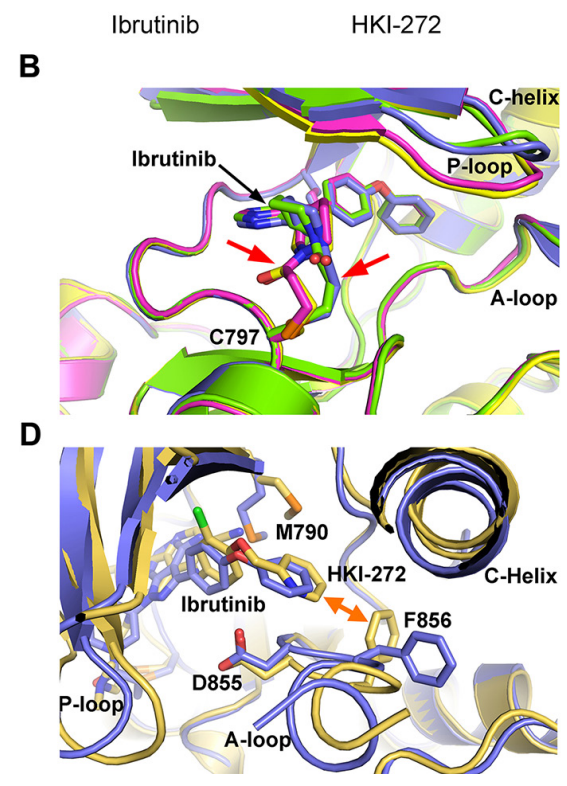

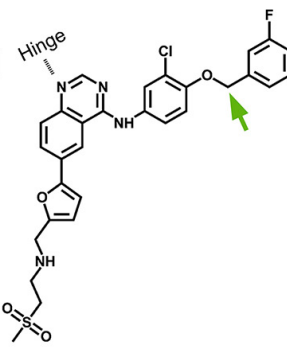

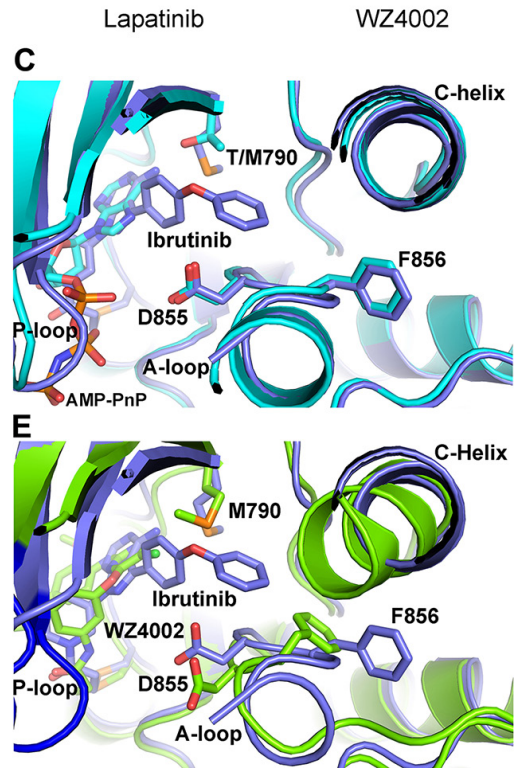

Figure 2: Crystal structure of EGFR T790M+ibrutinib and the comparison with other EGFR T790M+inhibitor co-crystal structures. (A) Chemical structures of Ibrutinib, HKI-272, Lapatinib and WZ4002 shown in the orientation roughly indicating their binding mode to EGFR. "Hinge" indicates the hinge peptide of EGFR that connects N-lobe and C-lobe of the kinase and interacts with the inhibitors through hydrogen bonds (indicated by dashed lines). The green arrows indicate the extra methylene in HKI-272 and Lapatinib. The purple arrow indicates the cyano group of HKI-272. (B) Superimposition of the four molecules in the asymmetric unit of the EGFR T790M+ibrutinib co-crystal structure. The red arrows indicate the slight difference between the two binding modes of ibrutinib. (C) Superimposition of the EGFR T790M+ibrutinib structure (slate) and the V948R+AMP-PnP structure (drawn from PDB ID 2GS7, cyan). (D) Superimposition of the EGFR T790M+ibrutinib structure (slate) and the T790M+HKI-272 structure (yellow). The double-headed orange arrow indicates the hydrophobic interaction between the inhibitor and the Phe856 side-chain. (E) Superimposition of the EGFR T790M+ibrutinib structure (slate) and the T790M+WZ4002 structure (green). 
while WZ4002 can bind to EGFR in active state and probably also in inactive state. What's more, to push the EGFR kinase from the ligand binding or mutation (such as L858R) induced active conformation toward inactive conformation would cost extra energy. These may explain why ibrutinib binds to EGFR less efficiently than does WZ4002.

\section{DISCUSSION}

Therefore, we postulated that the transient inhibitory activity of Ibrutinib against mutant EGFR Y1068 phosphorylation might be due to the distinct irreversible binding conformation formation since it required more binding energy to force the protein to adopt the DFG-in/c-Helix-out conformation. This phenotype is concentration dependent. At the same drug concentration, after removal of the drugs from the medium during the washing-out experiment, drug molecules that have already fitted the protein conformation while not yet formed the covalent bond would stay in the protein for longer time (residence time) since the protein required more energy to recover back to the normal state but eventually the drug will be released out from the protein complex due to the equilibrium between the inner cell and cell culture medium. This could explain why during the first several hours the phosphorylation of EGFR was continuously inhibited but then gradually got recovered then. In summary, the less efficiency of sustained inhibition of EGFR phosphorylation was due to the less efficient binding of ibrutinib to EGFR, but the distinct binding conformation gave ibrutinib a longer residence time on EGFR kinase, those ibrutinib molecules which did not form the covalent bond would be gradually released from the protein and hence resulted in the partial of the kinase activity recovery. Therefore an alternative Ibrutinib pharmacophore based scaffold would be needed in order to more efficiently stable the DFG-in/c-Helix out conformation and exert better-sustained inhibitory efficacy for the Y1068 site phosphorylation.

In summary, Ibrutinib inhibits mutant EGFR kinase through formation a covalent bond with Cys797, as other irreversible inhibitors, but due to an unusual DFG-in/c-Helix-out binding conformation, this irreversible binding is much less efficient than other irreversible EGFR inhibitors such as WZ4002. Considering the evidence that ibrutinib is highly potent in in vitro for EGFR mutant NSCLC cancer cell lines but only moderately slow down tumor progression in the mouse model, we propose that without alteration of the PK property of Ibrutinib itself, a specially designed formulation or dosage which can help sustain effective concentration should be considered to achieve the efficacy in the clinic application for mutant EGFR driven NSCLC.

\section{MATERIALS AND METHODS}

\section{Inhibitors}

Ibrutinib, W4002, CO-1686, AZD9291, Gefitinib were purchased from Haoyuan Chemexpress Inc. PCI-R was synthesized in the lab based on the procedure reported previously [1].

\section{Cell lines and cell culture}

The human cancer cell lines H1975, HCC827, and A549 cells were purchased from the American Type Culture Collection (ATCC) (Manassas, VA, USA). A431 was purchased from Cobioer Biosciences CO., LTD (Nanjing, China). H1975, HCC827 and EGFR mutant isogenic BaF3 cells lines were cultured in RPMI 1640 media (Corning, USA) with $10 \%$ fetal bovine serum (FBS) and supplemented with $2 \%$ L-glutamine and $1 \%$ penicillin/streptomycin. A549 was cultured in F-12K Nutrient Mixture (kaighn's Modification) (Gibco, USA), and A431 was cultured in DMEM media (Corning, USA) with $10 \%$ FBS and supplemented with $2 \%$ L-glutamine and $1 \%$ pen/strep. $\mathrm{H} 3255$ was cultured in BEGM media (LONZA, USA) with $10 \%$ FBS and supplemented with $2 \%$ L-glutamine and 1\% pen/strep. All cell lines were maintained in culture media at $37^{\circ} \mathrm{C}$ with $5 \% \mathrm{CO} 2$.

\section{Antibodies and immunoblotting}

The following antibodies were purchased from Cell Signaling Technology (Danvers, MA): EGF Receptor (D38B1) XP® Rabbit mAb(\#4267), Phospho-EGF Receptor (Tyr1068) (D7A5) XP® Rabbit mAb (\#3777), Antibodies were used at 1:1000.

\section{BaF3 isogenic cell line generation}

Retroviral constructs for $\mathrm{Ba} / \mathrm{F} 3-\mathrm{TEL}-\mathrm{EGFR}$ and $\mathrm{Ba} /$ F3-EGFR variants were made based on the pMSCVpuro (Clontech) backbone. For TEL-fusion vectors, the first $1 \mathrm{~kb}$ of human TEL gene with an artificial myristoylation sequence (MGCGCSSHPEDD) was cloned into pMSCVpuro retroviral vector, followed by a $3 \times$ FLAG tag sequence and a stop codon. Then the kinase domain coding sequences of EGFR variants were inserted in-frame between TEL and 3xFLAG sequences. For full-length expression vectors, the coding sequences of EGFR variants were directly cloned in pMSCVpuro vector with a $3 \times$ FLAG tag at the C-terminal end. All mutations were performed using the QuikChange Site-Directed Mutagenesis Kit (Stratagene) following the manufacturer's instructions. Retrovirus was made using the same method described above and was used to infect $\mathrm{BaF} 3$ cells. After puromycin selection, the IL-3 concentration in the medium was gradually withdrawn until cells were able to grow in the absence of IL-3. 


\section{Proliferation studies}

Cells were grown in 96-well culture plates (2500-3000/well). For adherent cell lines, compounds of various concentrations were added into the plates after cells were cultured for 12 hours. Cell proliferation was determined after treatment with compounds for 72 hours. Cell viability was measured using the CellTiter-Glo assay (Promega, USA), according to the manufacturer's instructions, and luminescence was measured in a multilabel reader (Envision, PerkinElmer, USA). Data were normalized to control groups (DMSO) and represented by the mean of three independent measurements with standard error $<20 \%$. $\mathrm{GI}_{50}$ values were calculated using Prism 5.0 (GraphPad Software, San Diego, CA).

\section{Washing out experiment}

H1975 cells were treated with ibrutinib $(0.3 \mu \mathrm{M}$, $1 \mu \mathrm{M}, 3 \mu \mathrm{M})$, WZ4002 $(0.3 \mu \mathrm{M}, 1 \mu \mathrm{M})$ for 4 hour before they were thoroughly washed out by PBS for three times. Then cells were incubated in 10\% FBS-containing RPMI1640 for indicated time before they are collected and lysed. EGFR, Phospho-EGFR (Tyr1068) antibody (Cell Signaling Technology) were used for immunoblotting.

\section{EGFR (L858R/T790M) protein purification}

A construct encoding EGFR residues 696-1022 with a GST tag was cloned into baculovirus expression vector pAcG2T. The protein was expressed by infecting SF9 cells with high titer viral stocks for $48 \mathrm{~h}$. Cells were harvested and lysed in $25 \mathrm{mM}$ Tris (pH 7.9), $150 \mathrm{mM} \mathrm{NaCl}$, and $1 \mathrm{mM}$ DTT. The supernatant was incubated with glutathione Sepharose beads (Genscript). After washing with wash buffer (40 mM Tris pH 7.9, $500 \mathrm{mM} \mathrm{NaCl}, 1 \%$ Glycerol, $1 \mathrm{mM}$ DTT), the beads were incubated overnight with $5 \mathrm{ml}$ wash buffer containing $5 \mathrm{ul} \mathrm{of} 5 \mathrm{mg} / \mathrm{ml}$ alphathrombin to remove GST tag. The eluted EGFR protein was loaded on desalt column PD-10(GE) to change the buffer to $25 \mathrm{mM}$ Tris pH7.5, $50 \mathrm{mM} \mathrm{NaCl}, 20 \mathrm{mM} \mathrm{MgCl}$, and $1 \mathrm{mM}$ DTT. The protein was concentrated to $1 \mathrm{mg} / \mathrm{ml}$ and aliquots were frozen and stored at $-80^{\circ} \mathrm{C}$.

\section{Biochemical binding Kd examination}

The Kd was measured using the Monolith NT.115 from Nanotemper Technologies. Proteins were fluorescently labeled according to the manufacturer's protocol. A range of concentrations of ligands Ibrutinib and WZ4002 (range from $0.05 \mathrm{mM}$ to $2.5 \mathrm{nM}$ ) were incubated with $200 \mathrm{nM}$ of purified EGFR T790M/ L858R protein $5 \mathrm{~min}$ in assay buffer $(50 \mathrm{mM}$ Tris, $200 \mathrm{mM} \mathrm{NaCl}, \mathrm{PH} 7.4$, and $0.05 \%$ Tween 20). The sample was loaded into the NanoTemper glass capillaries and microthermophoresis carried out using 20\% LED power and 20\% MST Power. Kd were calculated using the mass action equation via the NanoTemper software.

\section{Protein preparation and crystallization}

Construct of EGFR kinase domain (residues 696-1022) bearing the T790M mutation was PCR-cloned from the previously made GST-tagged EGFR T790M construct [15] and inserted into pFastBac HTA plasmid between the $\mathrm{NcoI}$ and $\mathrm{XhoI}$ restriction sites. Baculoviruse expressing the His-tagged EGFR 696-1022 T790M protein was then generated according to the official protocols of the pFastBac.

The His-tagged EGFR 696-1022 T790M protein was expressed in Sf9 insect cells. After harvesting, the cells were broken by sonication in lysis buffer $(20 \mathrm{mM}$ Tris, $150 \mathrm{mM} \mathrm{NaCl}, 3 \mathrm{mM} \mathrm{KCl}, 10 \%$ glycerol, $1 \mathrm{mM}$ PMSF, $1 \mathrm{mM}$ TCEP, $20 \mathrm{mM}$ Imidazole, $\mathrm{pH}$ 8.0, supplemented with Protease Inhibitors Cocktail (Sigma-Aldrich, Cat. S8830). Cell lysate was obtained by centrifugation at $20,000 \mathrm{rpm}$ for 1 hour at $4^{\circ} \mathrm{C}$ and then applied to the chelating sepharose beads (GE Healthcare, Cat. 17-0575-02) charged with $\mathrm{Ni}^{2+}$. The beads were thoroughly washed with wash buffer ( $20 \mathrm{mM}$ Tris, $500 \mathrm{mM} \mathrm{NaCl}, 1 \%$ glycerol, $0.5 \mathrm{mM}$ TCEP, $30 \mathrm{mM}$ Imidazole, $\mathrm{pH}$ 8.0), and then the protein was eluted with elution buffer $(20 \mathrm{mM}$ Tris, $500 \mathrm{mM} \mathrm{NaCl}, 1 \%$ glycerol, $0.5 \mathrm{mM}$ TCEP, $300 \mathrm{mM}$ Imidazole, $\mathrm{pH}$ 8.0). The affinity tags were removed by cleavage with TEV protease for 3 hours at $4{ }^{\circ} \mathrm{C}$, and the untagged EGFR proteins were collected from the flow-through of another pass through the Ni-beads. The eluent was concentrated and applied to gel-filtration chromatography using a Superdex 200 column (GE Healthcare, Cat. 17-5175-01) to further purify the protein. The purified protein was concentrated and dispensed into aliquots, flash-frozen in liquid nitrogen and stored in $-80^{\circ} \mathrm{C}$ freezer for later using.

For co-crystalization, $100 \mathrm{mM}$ ibrutinib solution was added to $8.8 \mathrm{mg} / \mathrm{mL}$ EGFR T790M protein solution to achieve the final concentration of $1 \mathrm{mM}$ compound. The mixture was incubated on ice for 2 hours to enable full labeling of EGFR with the compound before setting up the crystallization tray. The crystallization reservoir solution for $\mathrm{T} 790 \mathrm{M}+$ ibrutinib was $0.1 \mathrm{M}$ sodium citrate (pH 5.0), $12 \%$ PEG 10000 , and $3 \%$ dioxane, $5 \mathrm{mM}$ TCEP.

\section{Crystal structure determination and refinement}

The T790M+ibrutinib co-crystal diffraction data were collected at beamline BL17U1, Shanghai Synchrotron Radiation Facility at $100 \mathrm{~K}$. The X-ray wavelength for data collection was $0.97930 \AA$. The diffraction data were processed with HKL3000 [22]. The structure was solved by molecular replacement method with Phaser [23] using isolated N-lobe and C-lobe of the previously reported EGFR T790M structure (PDB 3IKA) as the 
search models. Simulated-annealing in CNS [24] was then used to obtain a less biased model and $2 \mathrm{Fo}-\mathrm{Fc}$ and Fo-Fc maps for manual inspection and adjustment. Repeated rounds of manual refitting and crystallographic refinement were performed using COOT [25] and Phenix [26]. The inhibitor was modeled into the closely fitting positive Fo-Fc electron density and then included in following refinement cycles. Topology and parameter files for the inhibitors were generated using PRODRG [27]. Reported by Ramachandran plots, the percentages of residues in the favored and allowed regions for the final refined structure are $98.1 \%$ and $1.9 \%$, respectively. No residues are in the outlier region. The structure was deposited in Protein Data Bank (PDB) with the entry IDs 4YNJ.

\section{ACKNOWLEDGMENTS AND FUNDING}

J. Liu is supported by the National Key Reasearch and Development Program of China (\#2016YFA0400900) and the National Program for Support of Top-Notch Young Professionals. J. Liu, Q. Liu, W. Wang and L. Cheng are supported by the grant of "Cross-disciplinary Collaborative Teams Program for Science, Technology and Innovation (2014-2016)" from Chinese Academy of Sciences. N. Gray is supported by NIH grant P01 CA154303-03. We want to thank China "Thousand Talents Program" support for Q. Liu and C. Wang; "Hundred Talents Program" of The Chinese Academy of Sciences support for J. Liu, and W. Wang. C.-H.Y. is funded by the National Science Foundation of China (No. 31270769) and the National Basic Research Program of China (973 Program, No. 2012CB917202). Q. Liu is also supported by the High-end User Cultivation Program of Hefei Science Center of CAS (\#2016HSC-IU007) and the CAS/SAFEA International Partnership Program for Creative Research Teams.

\section{CONFLICTS OF INTEREST}

Authors declare no conflicts of interest.

\section{REFERENCES}

1. Pan Z, Scheerens H, Li SJ, Schultz BE, Sprengeler PA, Burrill LC, Mendonca RV, Sweeney MD, Scott KC, Grothaus PG, Jeffery DA, Spoerke JM, Honigberg LA, et al. Discovery of selective irreversible inhibitors for Bruton's tyrosine kinase. Chem Med Chem. 2007; 2:58-61.

2. Hendriks RW, Yuvaraj S, Kil LP. Targeting Bruton's tyrosine kinase in B cell malignancies. Nat Rev Cancer. 2014; 14:219-232.

3. Wang ML, Rule S, Martin P, Goy A, Auer R, Kahl BS, Jurczak W, Advani RH, Romaguera JE, Williams ME, Barrientos JC, Chmielowska E, Radford J, et al. Targeting BTK with ibrutinib in relapsed or refractory mantle-cell lymphoma. N Engl J Med. 2013; 369:507-516.
4. Byrd JC, Furman RR, Coutre SE, Flinn IW, Burger JA, Blum KA, Grant B, Sharman JP, Coleman M, Wierda WG, Jones JA, Zhao W, Heerema NA, et al. Targeting BTK with ibrutinib in relapsed chronic lymphocytic leukemia. N Engl J Med. 2013; 369:32-42.

5. Herrera AF, Jacobsen ED. Ibrutinib for the treatment of mantle cell lymphoma. Clin Cancer Res. 2014; 20:5365-5371.

6. Woyach JA, Bojnik E, Ruppert AS, Stefanovski MR, Goettl VM, Smucker KA, Smith LL, Dubovsky JA, Towns WH, MacMurray J, Harrington BK, Davis ME, Gobessi S, et al. Bruton's tyrosine kinase (BTK) function is important to the development and expansion of chronic lymphocytic leukemia (CLL). Blood. 2014; 123:1207-1213.

7. Zhao X, Bodo J, Sun D, Durkin L, Lin J, Smith MR, Hsi ED. Combination of ibrutinib with ABT-199: synergistic effects on proliferation inhibition and apoptosis in mantle cell lymphoma cells through perturbation of BTK, AKT, BCL2 pathways. Br J Haematol. 2015; 168:765-768.

8. Rushworth SA, Murray MY, Zaitseva L, Bowles KM, MacEwan DJ. Identification of Bruton's tyrosine kinase as a therapeutic target in acute myeloid leukemia. Blood. 2014; 123:1229-1238.

9. Rushworth SA, Bowles KM, Barrera LN, Murray MY, Zaitseva L, MacEwan DJ. BTK inhibitor ibrutinib is cytotoxic to myeloma and potently enhances bortezomib and lenalidomide activities through NF-kappaB. Cell Signal. 2013; 25:106-112.

10. Gao W, Wang M, Wang L, Lu H, Wu S, Dai B, Ou Z, Zhang L, Heymach JV, Gold KA, Minna J, Roth JA, Hofstetter WL, et al. Selective antitumor activity of ibrutinib in EGFR-mutant non-small cell lung cancer cells. J Natl Cancer Inst. 2014; 106.

11. Honigberg LA, Smith AM, Sirisawad M, Verner E, Loury D, Chang B, Li S, Pan Z, Thamm DH, Miller RA, Buggy JJ. The Bruton tyrosine kinase inhibitor PCI-32765 blocks B-cell activation and is efficacious in models of autoimmune disease and B-cell malignancy. Proc Natl Acad Sci USA. 2010; 107:13075-13080.

12. Lanning BR, Whitby LR, Dix MM, Douhan J, Gilbert AM, Hett EC, Johnson TO, Joslyn C, Kath JC, Niessen S, Roberts LR, Schnute ME, Wang C, et al. A road map to evaluate the proteome-wide selectivity of covalent kinase inhibitors. Nat Chem Biol. 2014; 10:760-767.

13. Cohen MS, Zhang C, Shokat KM, Taunton J. Structural bioinformatics-based design of selective, irreversible kinase inhibitors. Science. 2005; 308:1318-1321.

14. Melnick JS, Janes J, Kim S, Chang JY, Sipes DG, Gunderson D, Jarnes L, Matzen JT, Garcia ME, Hood TL, Beigi R, Xia G, Harig RA, et al. An efficient rapid system for profiling the cellular activities of molecular libraries. Proc Natl Acad Sci USA. 2006; 103:3153-3158.

15. Yun CH, Mengwasser KE, Toms AV, Woo MS, Greulich H, Wong KK, Meyerson M, Eck MJ. The T790M mutation in EGFR kinase causes drug resistance by increasing the affinity for ATP. Proc Natl Acad Sci USA. 2008; 105:2070-2075. 
16. Zhang X, Gureasko J, Shen K, Cole PA, Kuriyan J. An allosteric mechanism for activation of the kinase domain of epidermal growth factor receptor. Cell. 2006; 125:1137-1149.

17. Wood ER, Truesdale AT, McDonald OB, Yuan D, Hassell A, Dickerson SH, Ellis B, Pennisi C, Horne E, Lackey K, Alligood KJ, Rusnak DW, Gilmer TM, et al. A unique structure for epidermal growth factor receptor bound to GW572016 (Lapatinib): Relationships among protein conformation, inhibitor off-rate, and receptor activity in tumor cells. Cancer Research. 2004; 64:6652-6659.

18. Walter AO, Sjin RT, Haringsma HJ, Ohashi K, Sun J, Lee K, Dubrovskiy A, Labenski M, Zhu Z, Wang Z, Sheets M, St Martin T, Karp R, et al. Discovery of a mutant-selective covalent inhibitor of EGFR that overcomes T790Mmediated resistance in NSCLC. Cancer Discov. 2013; 3:1404-1415.

19. Cross DA, Ashton SE, Ghiorghiu S, Eberlein C, Nebhan CA, Spitzler PJ, Orme JP, Finlay MR, Ward RA, Mellor MJ, Hughes G, Rahi A, Jacobs VN, et al. AZD9291, an irreversible EGFR TKI, overcomes T790M-mediated resistance to EGFR inhibitors in lung cancer. Cancer Discov. 2014; 4:1046-1061.

20. Yap TA, Popat S. Toward precision medicine with nextgeneration EGFR inhibitors in non-small-cell lung cancer. Pharmgenomics Pers Med. 2014; 7:285-295.

21. Zhou W, Ercan D, Chen L, Yun CH, Li D, Capelletti M, Cortot AB, Chirieac L, Iacob RE, Padera R, Engen JR, Wong KK, Eck MJ, et al. Novel mutant-selective EGFR kinase inhibitors against EGFR T790M. Nature. 2009; 462:1070-1074.
22. Minor W, Cymborowski M, Otwinowski Z, Chruszcz M. HKL-3000: the integration of data reduction and structure solution-from diffraction images to an initial model in minutes. Acta Crystallogr D Biol Crystallogr. 2006; 62:859-866.

23. McCoy AJ, Grosse-Kunstleve RW, Adams PD, Winn MD, Storoni LC, Read RJ. Phaser crystallographic software. J Appl Crystallogr. 2007; 40:658-674.

24. Brunger AT, Adams PD, Clore GM, DeLano WL, Gros P, Grosse-Kunstleve RW, Jiang JS, Kuszewski J, Nilges M, Pannu NS, Read RJ, Rice LM, Simonson T, et al. Crystallography \& NMR system: A new software suite for macromolecular structure determination. Acta Crystallogr D Biol Crystallogr. 1998; 54:905-921.

25. Emsley P, Lohkamp B, Scott WG, Cowtan K. Features and development of Coot. Acta Crystallogr D Biol Crystallogr. 2010; 66:486-501.

26. Adams PD, Afonine PV, Bunkoczi G, Chen VB, Davis IW, Echols N, Headd JJ, Hung LW, Kapral GJ, GrosseKunstleve RW, McCoy AJ, Moriarty NW, Oeffner R, et al. PHENIX: a comprehensive Python-based system for macromolecular structure solution. Acta Crystallogr D Biol Crystallogr. 2010; 66:213-221.

27. Schuttelkopf AW and van Aalten DM. PRODRG: a tool for high-throughput crystallography of protein-ligand complexes. Acta Crystallogr D Biol Crystallogr. 2004; 60:1355-1363. 